\title{
Platinum Nanoparticles for the Electrochemical Study of Heavy Metal ions Formed by the Sputtering Deposition of the ion beam Electrode
}

\author{
Ahmad Khalaf Alkhawaldeh ${ }^{1}$ \\ ${ }^{1}$ University of Jordan, Department of Chemistry, Amman - 11942, Jordan. \\ E-mail:Ahm9140096@fgs.ju.edu.jo, Ahmad.alkawalda@yahoo.com \\ Phone: 00962787455167
}

Corresponding author: Ahmad.alkawalda@yahoo.com

\begin{abstract}
An electrochemical sensing platinum nanoparticle in the tantalum electrode is provided by means of an Ion Beam Sputtering Deposition (IBSD). The electrode was made with a Pt solution, sputtered simultaneously with hydrochloric acid corrosion on tantalum substrate. In the study of heavy metal ions, for example, the platinum nanoparticle electrodes as prepared were used Square wavelength voltammetry (OSWV) $\mathrm{Hg}^{2+}, \mathrm{Cu}^{2+}$ and $\mathrm{Ag}^{2+}$. The porous electrodes were observed in a broader range by the $\mathrm{Pt}$ nanostructure electrode for heavy metal ions. Furthermore, the susceptibility to detection has been shown to be saturated as the thickness of the layer electrode exceeded $50 \mathrm{~nm}$. For $\mathrm{Hg}^{2+} 0,003-1 \mathrm{M}$, for $\mathrm{Cu}^{2+} 0,005-3$ $\mathrm{M}$ and for $\mathrm{Ag}^{2+}$ the linear detection scale is $0,009-4 \mathrm{M}$. There has also been good reusability and repeatability. In addition, a scan electron microscope (SEM) used to study platinum electrode forming process and nanostructure. This electrode will have interesting applications in sensing systems.
\end{abstract}

Keywords: Heavy metal, Platinum electrode, Ion beam sputtering deposition, Nanoparticle, IBSD, Ion detection.

\section{Introduction}

Due to its high degradability, aggregation in live species, which cause diverse diseases and genetic abnormalities, and deleterious ecological consequences, heavy metal ions pose a major threat to human health (Lin and Huang, 2017).

First, $\mathrm{Pb}^{2+}$ can lead to a wide variety of health conditions, including diarrhea, convulsions, vomiting, and insufficiency of the kidneys, tumors and negative metabolism. (Hourani and Alkawaldeh, 2016).

Excessive $\mathrm{Cu}^{2+}$ can also be blamed for other illnesses, including hemochromatosis, catarrh, calf cramps, scalp dermatitis brass chills and Wilson's (Strmčnik et al, 2019).

Several methods have been employed for detecting heavy metal ions, for instance, the use of atomic electron emission spectrometry (ICP / AES, ICP / MS), flow-injection spectroscopy (FIAAS), and high resolution liquid chromatography (HPLC) (Altweiq and Alkhawaldeh, 2019).

However, where the concentration spectrum of these metal ions is wide, it is difficult to examine specifically heightened metal ions using these techniques. Therefore, it is urgently necessary to build metal ion sensors with a broader range of detections and high sensitivity. Graphene is a single-atomic layer of tightly packed carbon atoms in a two-dimensional wave (Cao et al, 2008). 
Due to its high electronic mobility, wide surface area and the prevalence of exposed edge planes for greatly raising the storage of charges, platinum has tremendous potential to be used in the production of chemo sensors (Khedher et al, 2012).

The wide range of catalytic, sensor and plasma resonance applications have drawn tremendous attention for porous substances, such as porous gold with a high volume-to-surface ratio, strong electrical and thermal conductivity and a high catalytic performance (Kokkinos et al, 2008).

Porous gold has recently been shown to be a highly efficient catalyst for many primary reactions such as low-temperature $\mathrm{CO}$ oxidation, electrical oxidation, and reduction of oxygen-based hydrogen peroxide (Alkhawaldeh et al., 2020).

A variety of methodologies have been studied to prepare pore structures, including wet impregnation, relocation, solvent fusion and particulate leaching, rough anodization and magnetron sputtering ( ).

The specific feature of the Ion beam sputtering (IBSD) process is the capacity to deposit high-density films at a low substratum temperature through the dynamics for atomic or molecular transport growth mechanism, which gives it numerous benefits including excellent stoichiometry movement, strong durability and simple set-up for the creation of films ( ).

The platinum nanoelectrode was rendered in tantalum surface by IBSD and a novel electrode was then used for electrochemical study of heavy metal ions.

\section{Materials and Apparatus}

Shandong Laiyang Economic and Technologi are bought with hydrochloric acid (37\%), neritic acid (98\% AR), ammonium acetate (AR), persulfate potassium (AR), oxide phosphate (V) (98\%), permanganate potassium (AR), peroxide hydrogen (30\%), ethanol (AR), sodium nitrate (AR), and diethyl ether (AR). The Tianjin Aida Hengsheng Manufacturing was acquired with platinum electrode fittings (diameter $6 \mathrm{~mm}$ ), platinum foil auxiliary and $\mathrm{Ag} / \mathrm{AgCl}$ reference electrodes. Zhuhai Kaivo Electronic Components purchased tantalum tiles. Qingdao Heli Gas bought ultra-pure nitrogen (99.999\%).

Flam's ultra-pure water device was developed. Images from a scan-electron microscope were obtained using a JEOL JSM-6700F electron-scan microscope with an accelerated voltage of $5 \mathrm{kV}$. An EDS detector attached to the above-mentioned SEM microscope, Oxford INCA Sight-X, has been used to carry out energy dispersion testing (EDS).

The concustomized three-electrode cell with the electrochemical workstation CHI-760D (CHI Devices, Shanghai, China) was used to perform all electrochemical measurements. At least 15 minutes prior to data collection, the solution had been degassed with nitrogen and blanketed with nitrogen over the completely experimental phase.

At room temperatures, all capacity is reached in an electrical one-compartment cell. The IBSD was made of platinum nanoparticle electrode. The electrodes were cleaned thoroughly and dried in oven prior to use with ultra-pure water.

\section{Detection of metal ions}

The Square Wave Voltammetry of Oster young (OSWV) has been used in order to illustrate realistic applications of the platinum nanoparticle electrode, to evaluate $\mathrm{Hg} 2+, \mathrm{Cu} 2+$ and $\mathrm{Ag} 2+$ solutions that are 
more sensitive than differential pulse voltammetry because of the improved reverse reaction sensibility. A mixture of a square wave series with an escalator waveform is the ideal waveform for OSWV.

On each square-wave period, the current is sampled twice, one at the end of the forward pulse and one at the end of the opposite pulse. $\mathrm{Hg} 2+, \mathrm{Cu} 2+$ and $\mathrm{Ag} 2+$ solutions were reduced in stock solutions at various rates. The electrodes were washed in an ammonium acetate buffer to ensure complete separation of all the ions with OSWV in transparent solutions of an ammonium acetate buffer.

\section{Results and discussion}

The composition and the cross-section of the electrodes is characterized by the use of SEM testing to ensure the effectiveness of the platinum nanoparticle on the tantalum composition. Figure 1 shows that the electrode is flat and Pt is compacted very tightly. Nevertheless, after hydrochloric corrosion, the microstructure was obtained and pore is distributed similarly. It is very uniform in its dimensions and has a diameter of around $40-75 \mathrm{~nm}$.

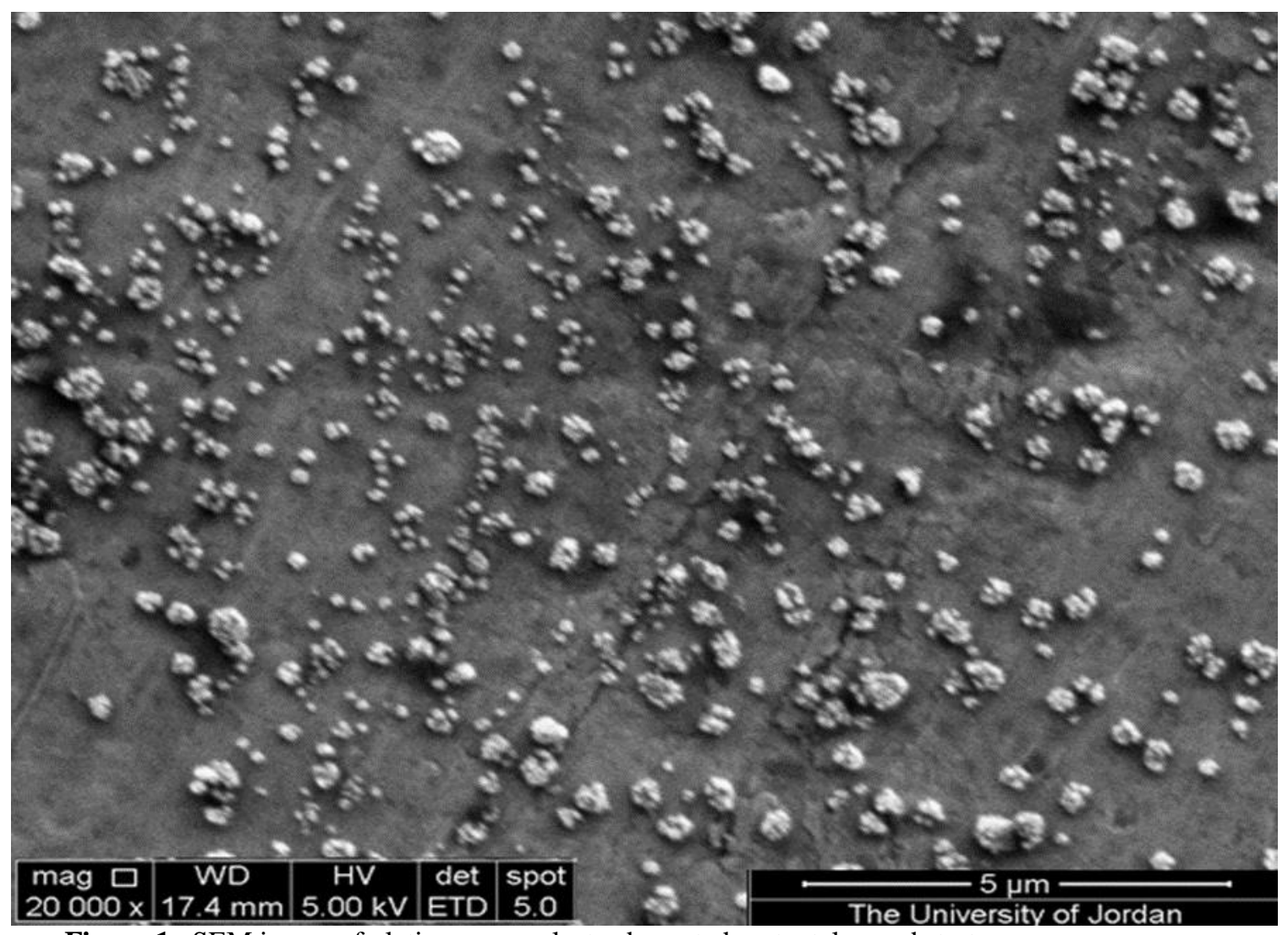

Figure 1. SEM image of platinum nanoelectrode coated on tantalum substrate.

In the preparation of the composite target on Ta top, SEM was used to describe the platinum nanoelectrode. In about $150 \mathrm{~nm}$ to $1 \mathrm{~m}$ of the SEM picture, the individual platinum surface was nearly 
translucent. The thickness of this Pt nanoelectrode is relatively uniform, and about $32 \mathrm{~nm}$ in diameter, as seen in Figure 1.

One of the most important research techniques for metal ions identification in natural, health and industrial samples is electrochemical research. Possibly, due to special Pt nanostructures and the modern tantalum coating, the electrochemical calculation using platinum nanoelectrode shows enhanced detection range and greatly increased the real area of the electrode allowing more metal ions to react to the electrode.

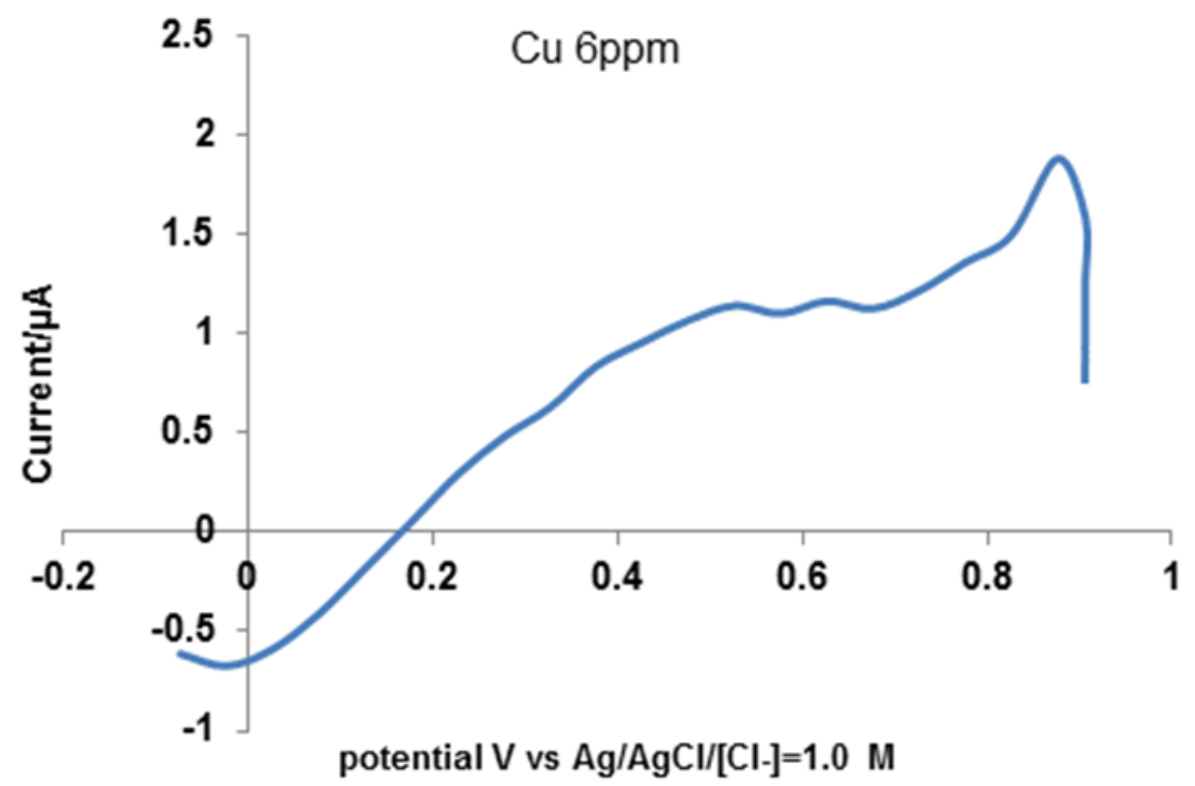

Figure 2. cyclic voltammograms of $\mathrm{Cu} 2+$ solutions with $6 \mathrm{ppm}$ concentration using the Platinum nanoelectrode at a scan rate of $50 \mathrm{mV} \mathrm{s}^{-1}$.

As shown in Figure 2, the platinum nanoelectrode detects $\mathrm{Cu} 2+$ with a buffer solution for ammonium acetate $(\mathrm{pH}=5)$, that is used as a model analytic. Since Oster young square wave voltammetry (OSWV) typically has greater analytical sensitivity, all detections were performed using OSWV in the sample for all heavy metal ions. $\mathrm{Cu}^{2+}$ solutions with various rates have been reported from $0.0 \mathrm{~V}$ through $0.38 \mathrm{~V}$ in a potential window. The prominent peak range from $0.81-0.92 \mathrm{~V}$ to the reference electrode $\mathrm{Ag} / \mathrm{AgCl}$ has been described to deliver well-defined peaks. 


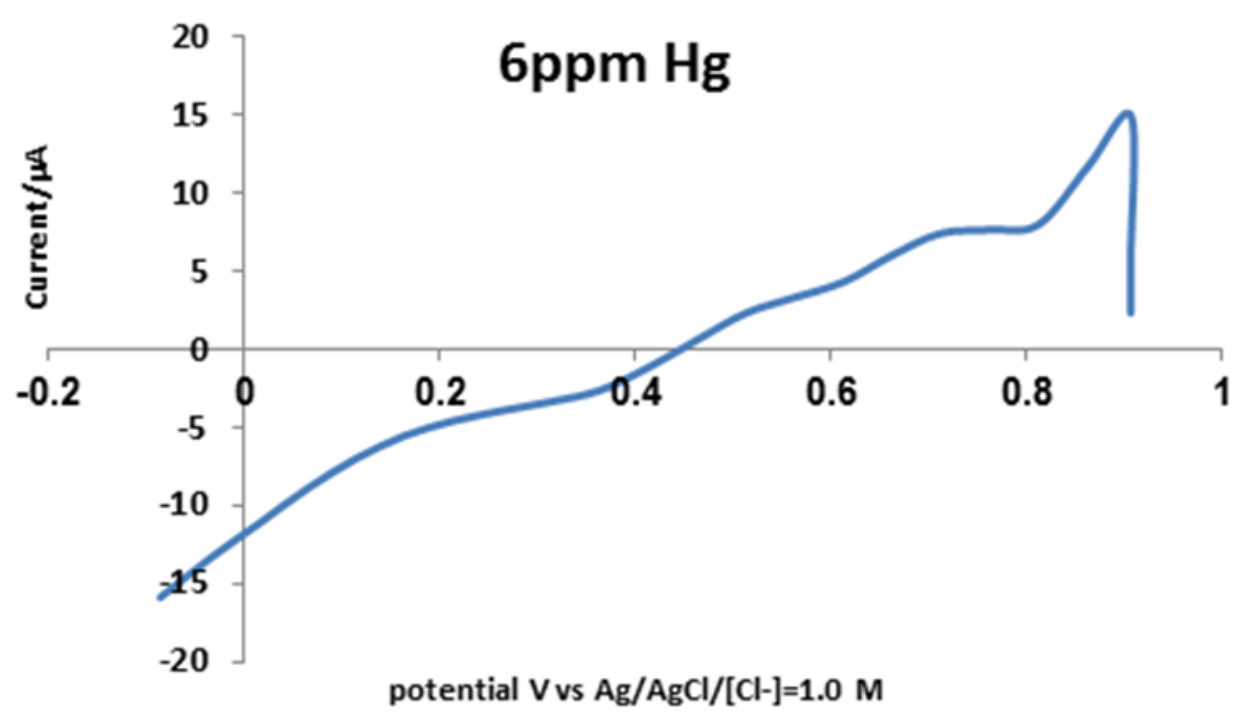

Figure 3. cyclic voltammograms of $\mathrm{Hg}^{2+}$ solutions with $6 \mathrm{ppm}$ concentration using the Platinum nanoelectrode at a scan rate of $50 \mathrm{mV} \mathrm{s}^{-1}$.

Also, in a potential window from $\mathrm{Hg} 2+(0.84$ to $0.9 \mathrm{~V}) \mathrm{Ag} 2+(0.31-0.39 \mathrm{~V})$ and the use of the platinum nanoelectrode using the OSWV system (Figure 3 and 4) the $\mathrm{Hg} 2+$ and $\mathrm{Ag} 2+$ solutions of different concentration were analyzed.

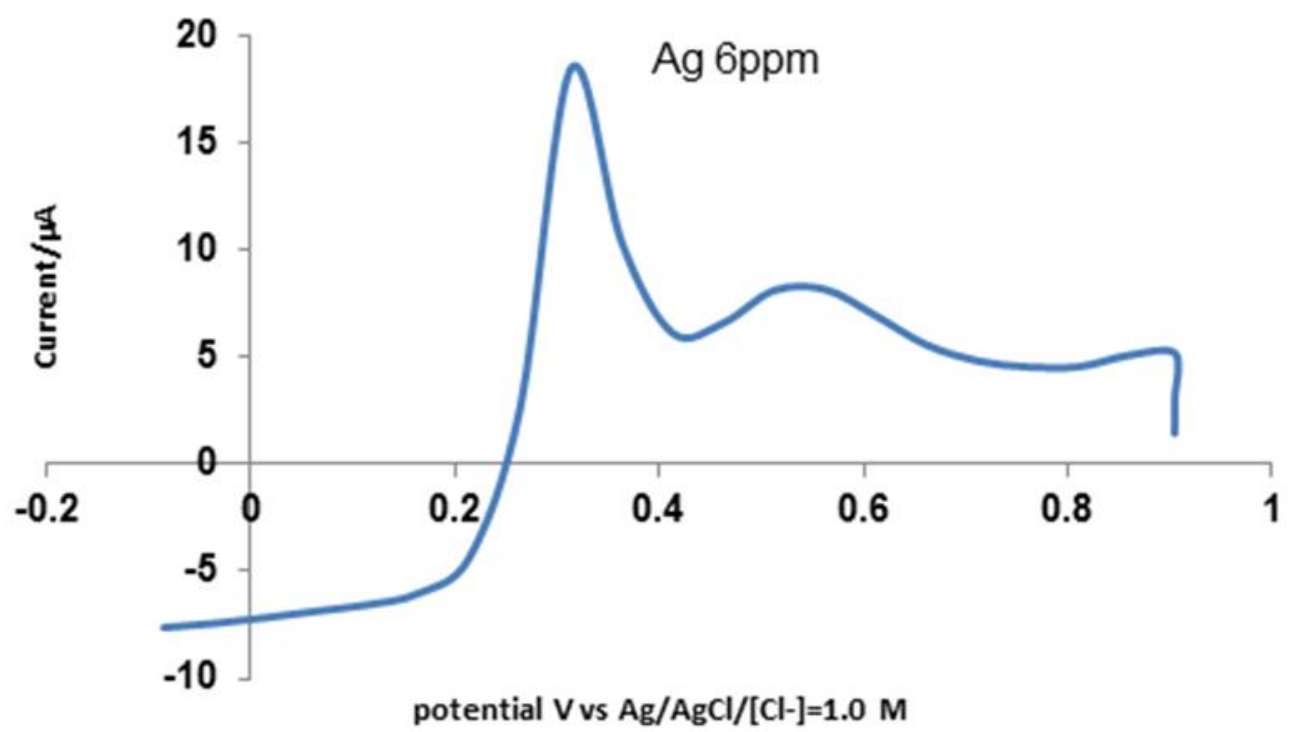

Figure 4. Cyclic voltammograms of $\mathrm{Ag} 2^{+}$solutions with $6 \mathrm{ppm}$ concentration using the Platinum nanoelectrode at a scan rate of $50 \mathrm{mV} \mathrm{s}^{-1}$. 
The reaction of the electrode to $\mathrm{Ag} 2+$ can be observed as being more active than the detection limit $(\mathrm{Cu} 2+$ and $\mathrm{Hg} 2+)$ of $8 \mathrm{nM}$. Figure 5 indicates the trajectory of peak current versus concentrations of $\mathrm{Hg} 2+$, $\mathrm{Cu} 2+$ and $\mathrm{Ag} 2+$.

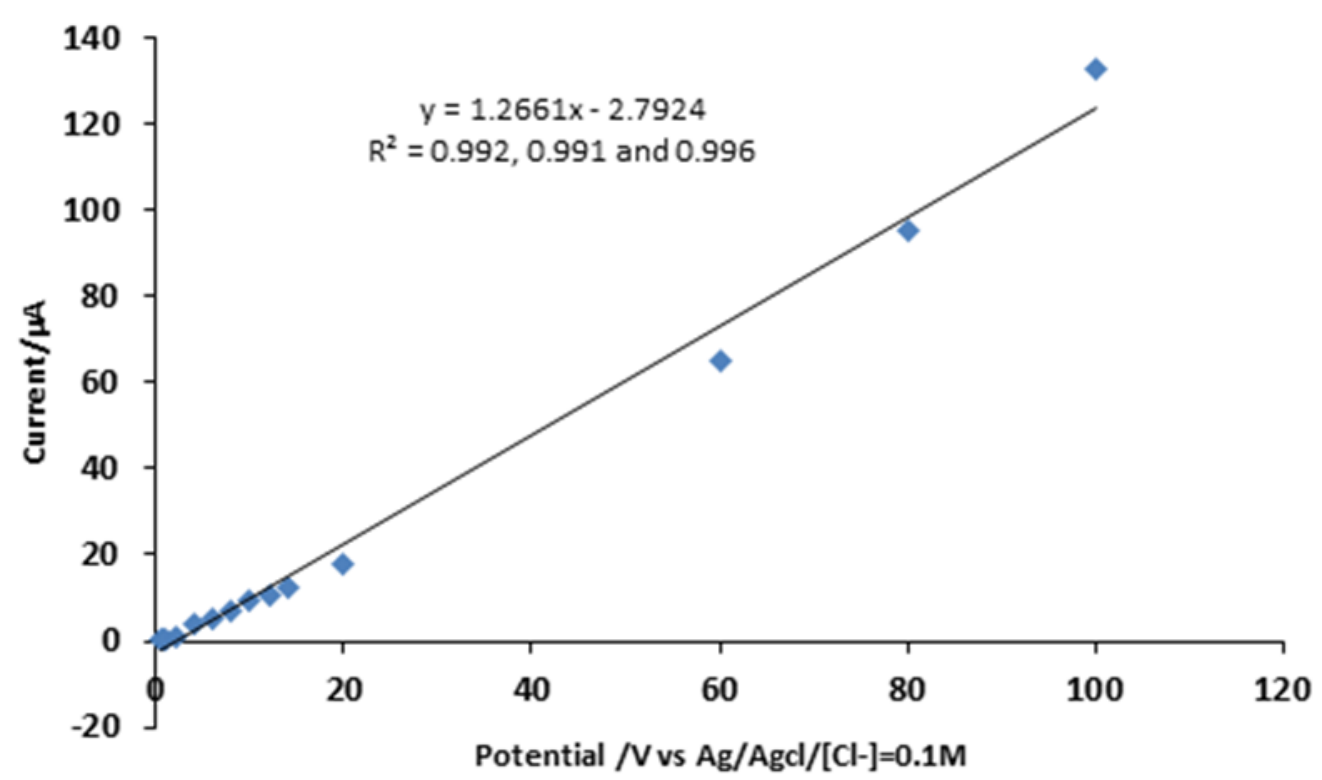

Figure 5. Plot peak current versus concentrations of $\mathrm{Hg}^{2+}, \mathrm{Cu}^{2+}$ and $\mathrm{Ag}^{2+}$ at a scan rate of $50 \mathrm{mV} \mathrm{s}^{-1}$.

The prepared electrode was observed to range from 0.009-4 M, 0.005-3 M and 0.003-1 M respectively to a linear detection of $0.992,0.991$ and 0.996 . In contrast, other sensors have previously recorded the detection efficiency of $\mathrm{Hg} 2+, \mathrm{Cu} 2+$ and $\mathrm{Ag} 2+$. It is clear that the range of detection of our research is superior to other studies, but comparable to some other tests. Platinum nanoparticles electrode stability was tested for 7 days, 14 days and 40 days respectively while keeping the electrodes at room temperature. Platinum nanoelectrode OSWVs have been reported in the ammonium acetate buffer $(\mathrm{pH}=5.0)$ with $2.5 \mathrm{M}$ $\mathrm{Hg}^{2+}, \mathrm{Cu}^{2+}$ and $\mathrm{Ag}^{2+}$ solutions. In the first two weeks, as seen in Figure 6, just 4.1 percent was deteriorated. After 40 days, the sensitivity of the electrode was still greater than $82.1 \%$. 


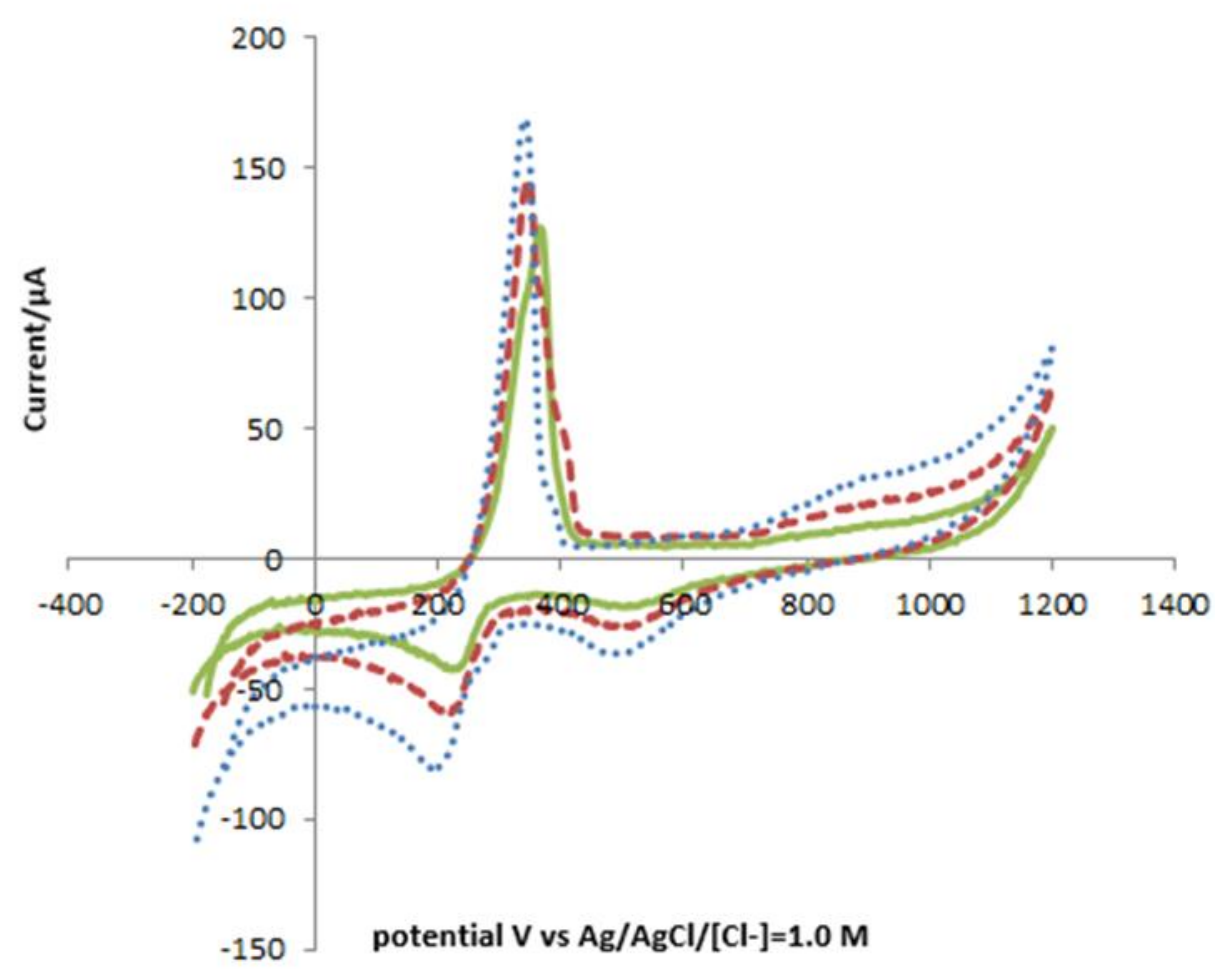

Figure 6. OSWVs of $2.5 \mathrm{M} \mathrm{Ag}^{2+}$ ammonium acetate solution using the platinum nanoelectrode with different days.

Ultrasound therapy has also been tested for the stability of platinum nanoelectrode. The sensitivity of $\mathrm{Hg}^{2+}, \mathrm{Cu}^{2+}$ and $\mathrm{Ag}^{2+}$ to detect also exceeded $76.6 \%$ by $82.4 \%$ and $92.6 \%$ after ultrasonic therapy in the clean ammonium buffer $(\mathrm{pH}=5.0)$, for $10 \mathrm{~min}$. The platinum nanoparticles were found to be solid enough for replicable study in tantalum surface electrodes.

\section{Conclusions}

In summary, a new method for the manufacture of platinum nanoparticle electrode with a tuning thickness has been successfully produced through ion beam sputters and chemical corrosion. The heavymetal ion measurement sensitivity was proportional to the pore electrode's thickness and completely saturated after $50 \mathrm{~nm}$.

With the added thickness of the porous electrode, the analytical exposure to heavy metal ions is improved. Of $\mathrm{Cu} 2+, 0.005-3 \mathrm{M}$ for the $\mathrm{Ag}^{2+}$ analysis and 0.009-4 $\mathrm{M}$ for the $\mathrm{Hg} 2+$, the linear detection range is $0.003-1 \mathrm{M}$. Such electrodes were also stable, reusable and anti-interfering. 


\section{References}

Alkhawaldeh, A. K. (2020). Analytics of Antimony in Natural Water of Nanoparticle Platinum Electrode by Application Square Wave Voltammetry, International Journal of Multidisciplinary Sciences and Advanced Technology, 1(4): 96-103.

Alkhawaldeh, A. K. (2020). Electrical Conductivity of Natural Volcanic Tuff Mix by Cyclic Voltammetry Method, International Journal of Multidisciplinary Sciences and Advanced Technology, 1(5): $37-44$.

Alkhawaldeh, A. K. (2020). Platinum Nanoparticle in Tantalum Electrode for the Electrochemical Analysis of Heavy Metal Ions, International Journal of Intelligent Computing and Technology, 4(1): 25-35.

Alkhawaldeh, A. K. (2020). Platinum Nanoparticles for the Electrochemical Study of Heavy Metal ions Formed by the Sputtering Deposition of the ion beam Electrode. International Journal of Engineering and Artificial Intelligence. 1(3): 1-8.

Alkhawaldeh, A. K. Alkhawaldeh, R. (2020). Highly Sensitive copper Heavy Metal Analysis on Nanoparticle Platinum and palladium electrode, International Journal of Engineering and Artificial Intelligence. 1(2): 33-39.

Alkhawaldeh, A. K., M.Krishan, M., Altwaiq, A., Dabaibeh, R. N. (2020). Preparation of Nanostructured/ Microplatinum Surfaces by Application of a Square Wave Potential Regime for Methanol Oxidation. Eurasian Journal of Analytical Chemistry, 15(1), emEJAC-00362.

Al-Khedher, M. A., Pezeshki, C., Mchale, J. L., \& Knorr, F. J. (2012). Empirical Modeling of Nanoindentation of Vertically Aligned Carbon Nanotube Turfs using Intelligent Systems. Fullerenes, Nanotubes and Carbon Nanostructures, 20(3), 200-215. doi: 10.1080/1536383x.2010.542590.

Almatarneh, M. H., Elayan, I. A., Al-Sulaibi, M., Khawaldeh, A., Saber, S. O. W., Al-Qaralleh, M., and Altarawneh, M. (2019). Unimolecular Decomposition Reactions of Propylamine and Protonated Propylamine. ACS Omega, 4(2), 3306-3313. doi: 10.1021/acsomega.8b02792.

Alshamaileh, E., Al-Sulaibi, M., Al-Khawaldeh, A., Almatarneh, M., El-Sabawi, D. and Al-Rawajfeh, A. (2016), "Current status of nanotechnology in Jordan", World Journal of Science, Technology and Sustainable Development, Vol. 13 No. 2, pp. 66-81. https://doi.org/10.1108/WJSTSD-01-2016-0001.

Altweiq, A. and Alkhawaldeh, A (2019). The Determination of Some Heavy Metals in Different Selected Diets. Eurasian Journal of Analytical Chemistry, 14(4), emEJAC-00326.

Cao, L., Jia, J., \& Wang, Z. (2008). Sensitive determination of $\mathrm{Cd}$ and $\mathrm{Pb}$ by differential pulse stripping voltammetry with in situ bismuth-modified zeolite doped carbon paste electrodes. Electrochimica Acta, 53(5), 2177-2182. doi: 10.1016/j.electacta.2007.09.024.

Hourani, M. K. and Alkawaldeh A. (2016). Synergistic Effects of Bismuth Adatoms on Electrocatalytic Properties of Electrodeposited Nanostructured Platinum Electrodes. International Journal of Electrochemical Science, 3555-3566. doi: 10.20964/110434.

Kokkinos, C., Economou, A., Raptis, I., \& Efstathiou, C. E. (2008). Lithographically fabricated disposable bismuth-film electrodes for the trace determination of $\mathrm{Pb}(\mathrm{II})$ and $\mathrm{Cd}$ (II) by anodic stripping voltammetry. Electrochimica Acta, 53(16), 5294-5299. doi: 10.1016/j.electacta.2008.02.079. 
Krishan, M.; Alkhawaldeh, A.; Soliman, A. (2019). Development of Nitride-Sensors for Monitoring in Control Systems. Preprints, 2019050227.

Laschi, S., Palchetti, I., \& Mascini, M. (2006). Gold-based screen-printed sensor for detection of trace lead. Sensors and Actuators B: Chemical, 114(1), 460-465. doi: 10.1016/j.snb.2005.05.028.

Lin, S.-L., \& Huang, W.-C. (2017). Chelation Therapy Has a Beneficial Effect in Ultrasonic Endothelial Function in Patients with Elevated Serum Lead or Cadmium Levels. Ultrasound in Medicine \& Biology, 43. doi: 10.1016/j.ultrasmedbio.2017.08.1930.

Strmčnik, E., Majdič, F., \& Kalin, M. (2019). Influence of a Diamond-Like Carbon-Coated Mechanical Part on the Operation of an Orbital Hydraulic Motor in Water. Metals, 9(4), 466. doi: 10.3390/met9040466. 